\title{
An Integrated College Faculty Recruitment System
}

\author{
C. Siva Kumar'1, L. Sharath Kumar², C. Muthyalappa², D. Y. Shruthi², S. Shareena², D. Sireesha ${ }^{2}$ \\ ${ }^{1}$ Associate Professor, Department of Computer Science and Engineering, Sanskrithi School of Engineering, \\ Puttaparthi, Andhra Pradesh, India \\ 2B. TECH. Student, Department of Computer Science and Engineering, Sanskrithi School of Engineering, \\ Puttaparthi, Andhra Pradesh, India
}

\begin{abstract}
Article Info
Volume 8, Issue 3

Page Number : 632-637

Publication Issue

May-June-2021

Article History
\end{abstract}

Accepted : 10 June 2021

Published : 15 June 2021

\begin{abstract}
College Faculty Recruitment System android application will be the best tool that helps in sorting out the candidates and giving best results out of recruitment cycle. One of the main features of college faculty recruitment system android application is sort out candidates and make candidates to write test through our application. If they have cleared test then they will get shortlisted by college management for the further rounds to be get selected for the job role. Candidates will be selected finally with their overall performance in the rounds provided by the college management.
\end{abstract}

Keywords : Diabetes, Medicinal Plant, Hypertension, Blood Glucose Level

\section{INTRODUCTION}

Recruitment is considered among the most challenging functions for job portals and human resource (HR) departments. This is because employers often receive a huge number of resumes - some of which are uploaded as unstructured documents in different formats such as .pdf, doc, and. rtf, while others are uploaded according to specific forms prepared by employers that are difficult to manually process and analyze. Recently, many companies have shifted to automatic online recruitment systems in an attempt to reduce the cost, time, and efforts required for screening out applicants and matching candidate resumes to their relevant job posts. As reported by SAT telecom, the use of online recruitment has led to
$44 \%$ of cost savings and reduced the time to fill a vacancy from 70 to 37 days.

\section{OBJECTIVE}

This proposed system aims atidentifying the Right Candidate for the Position from a huge number of profiles which is very difficult and consumes a huge man power and a large amount of time. So that, the Recruitment process will get slowed down and then the candidates may not be taken based on the skills because of the urgencies. This proposed system will develop a Recruitment system which can make the process of recruiting easy, by selecting skilled candidates from all over the remote places. 


\section{EXISTING SYSTEM}

Hiring is one of the most commonly performed by educational sector, companies and different organizations. This model works on the basis of certain negotiated terms \& conditions with employees or clients and providing the educational sector with employees on a required basis. It incorporates the employee with an ongoing recruitment \& placement action manually.

\section{DRAWBACKS:}

It can take the lot of time to recruit the candidate. Human Efforts may loss and can be variant.Fresh Recruiters can make mistakes due to lack of skills for the required job (By manual recruitment).

\section{PROPOSED SYSTEM:}

Our Proposed system can make the recruitment process easy; by using the conducting the online assessments and sorting out efficient candidatures for college. Here the resume evaluation can be done by analyzing the details entered by the user at the time of registration, Once the candidate gets registered, he needs to login into the app and our application will arrange a test based on his inputs he has given at the time of registration. After completing test, he can check results and let they can know that they are shortlisted or not. Admin side he can set questions for tests from our application and can check status of tests and if candidates appeared test successfully, Admin can shortlist or not to shortlist based on their test performance.

\section{ADVANTAGES}

There is a chance to use the proper time and no usage if human efforts. This is so accurate and efficient.

This will make easy to recruit from the remote areas and make easy to search by locations. This can be used in all kind of android devices with ease. It can be a lot helpful to HOD's and College Management for their recruitment process.

Hiring Process can be eased in recruitments and drives.

\section{LITERATURE SURVEY}

In our literature survey, we underscore the system refines the lists of concepts through removing those that appear to be of little value and don't have significant meaning in the matching process. By this we mean concepts that express features such as: candidate's name, address, contact info, etc. In addition, concepts that have low tf-idf weights are removed as detailed in section four. Next, the third module of the proposed system takes the refined lists of concepts (from the segments of both the job posts and resumes) as input to construct semantic networks in which concepts are connected by various types of semantic.

\section{[1].Domain driven data mining in human resource management: A review of current research}

An increasing number of publications concerning data mining in the subject of human resource management (HRM) indicate the presence of a prospering new research field. The current paper reviews this research on $\mathrm{HR}$ data mining to systematically uncover recent advancements and suggest areas for future work. Based on the approach of domain driven data mining, an initial framework with significant domain-specific requirements is elaborated. Relevant research contributions are identified and reviewed against the background of this framework. The review reveals that HRM constitutes a noteworthy new domain of data mining research that is dominated by method- and technology-oriented work. However, specific domain requirements, such as evaluating the domain success or complying with legal standards, are frequently not recognized or considered in current research. Therefore, the systematic consideration of domain- 
specific requirements is demonstrated here to have significant implications for future research on data mining in HRM.

\section{[2]. A hybrid approach to managing job offers and candidates}

The evolution of the job market has resulted in traditional methods of recruitment becoming insufficient. As it is now necessary to handle volumes of information (mostly in the form of free text) that are impossible to process manually, an analysis and assisted categorization are essential to address this issue. In this paper, we present a combination of the E-Gen and Cortex systems. E-Gen aims to perform analysis and categorization of job offers together with the responses given by the candidates. E-Gen system strategy is based on vectorial and probabilistic models to solve the problem of profiling applications according to a specific job offer. Cortex is a statistical automatic summarization system. In this work, E-Gen uses Cortex as a powerful filter to eliminate irrelevant information contained in candidate answers. Our main objective is to develop a system to assist a recruitment consultant and the results obtained by the proposed combination surpass those of E-Gen in standalone mode on this task.

\section{[3].The impact of semantic web technologies on job recruitment processes}

Using Semantic Web Technologies in the domain of online recruitment could substantially increase market transparency, lower the transaction costs for employers, and change the business models of the intermediaries involved. In this paper, we describe how online recruitment processes can be streamlined using Semantic Web technologies. We analyze the realization chances of such a scenario from the technological and business viewpoint. We describe a prototypical implementation of the required technological infrastructure and analyze the potential economic impacts, the interests of the involved parties and potential changes to their business models.

\section{USE CASE DIAGRAM:}
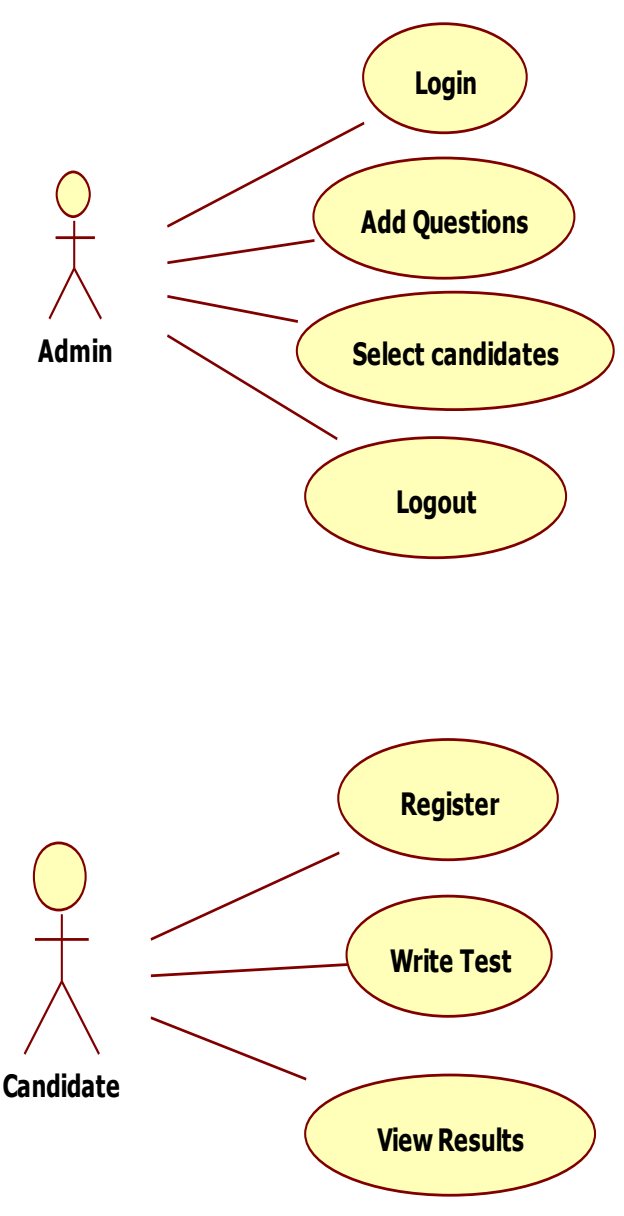

Use case diagrams which are model behavior within a system and helps the developers to understand of what the user require. Its purpose is to present a graphical overview of the functionality provided by a system in terms of actors, their goals (represented as use cases), and any dependencies between those use cases. The main purpose of a use case diagram is to show what system functions are performed for which actor. Roles of the actors in the system can be depicted. The stick man represents what's called an actor. Use case diagram can be useful for getting an overall view of the system and clarifying who can do and more importantly what they can't do 
Use case diagram consists of use cases and actors and shows the interaction between the use case and actors.

\section{SYSTEM REQUIREMENTS:}

\section{Software Requirements:}

Operating System : Windows and

Android

SDK Ide : Android Studio 4.2

Programming Language : Java

Front End : Xml

Server scripting Language : PHP

Database : MySQL

\section{Hardware Requirements:}

CPU type : Intel i5,i7

Ram size : $8 \mathrm{~GB}$

Hard disk capacity : 1TB

Monitor

: 15 Inch colourmonitor

Keyboard type

: internet keyboard

Mobile : Android

\section{BLOCK DIAGRAM:}

This block diagrams explains about how the recruitment process can be done through our proposed system.

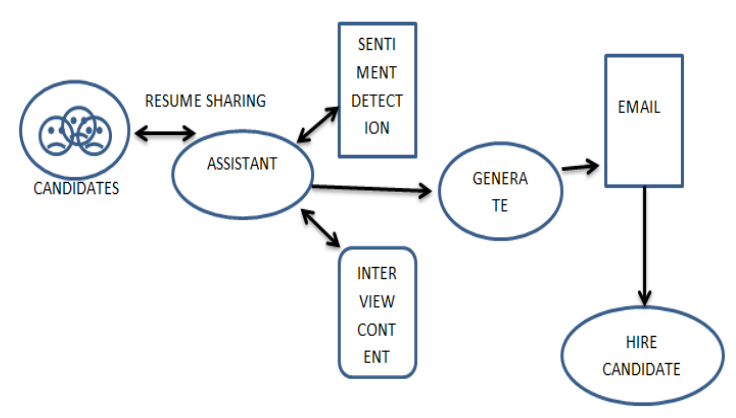

\section{OUTPUT SCREENSHOTS:}

\section{Welcome Screen}

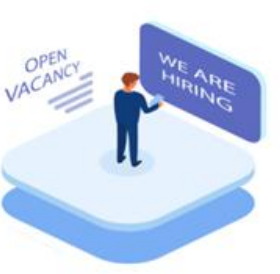

Welcome to College Faculty Recruitment System

Login Screen

\section{Login}
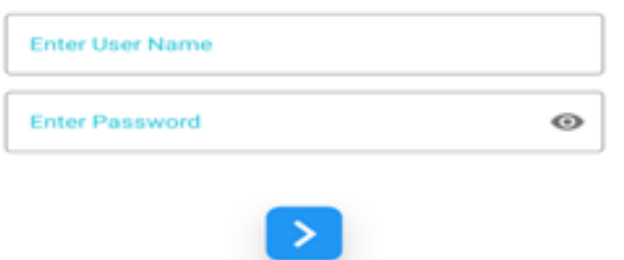

New Candidate?

User Screens

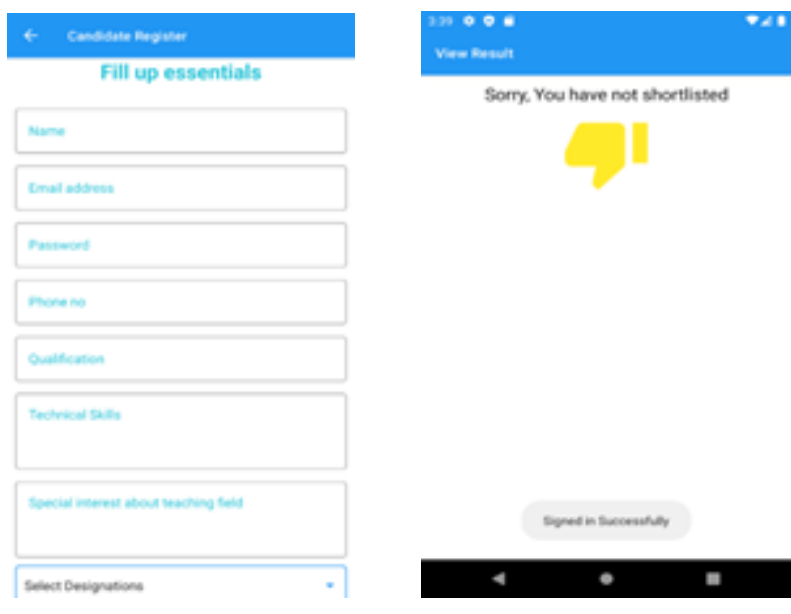


C. Siva Kumar et al Int J Sci Res Sci \& Technol. May-June-2021, 8 (3) : 632-637

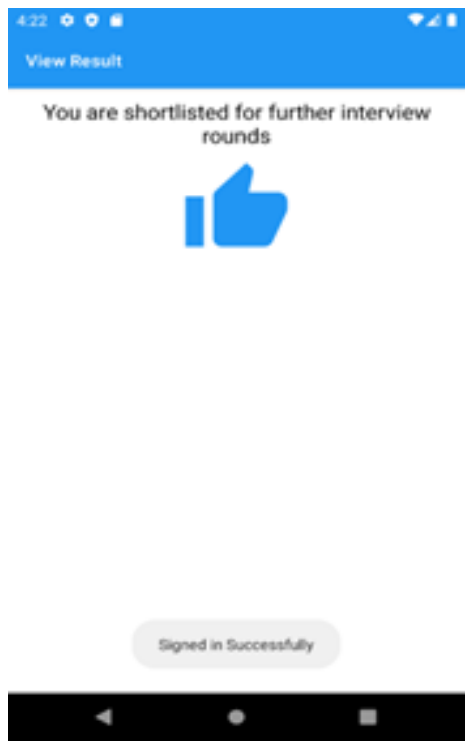

Admin screens
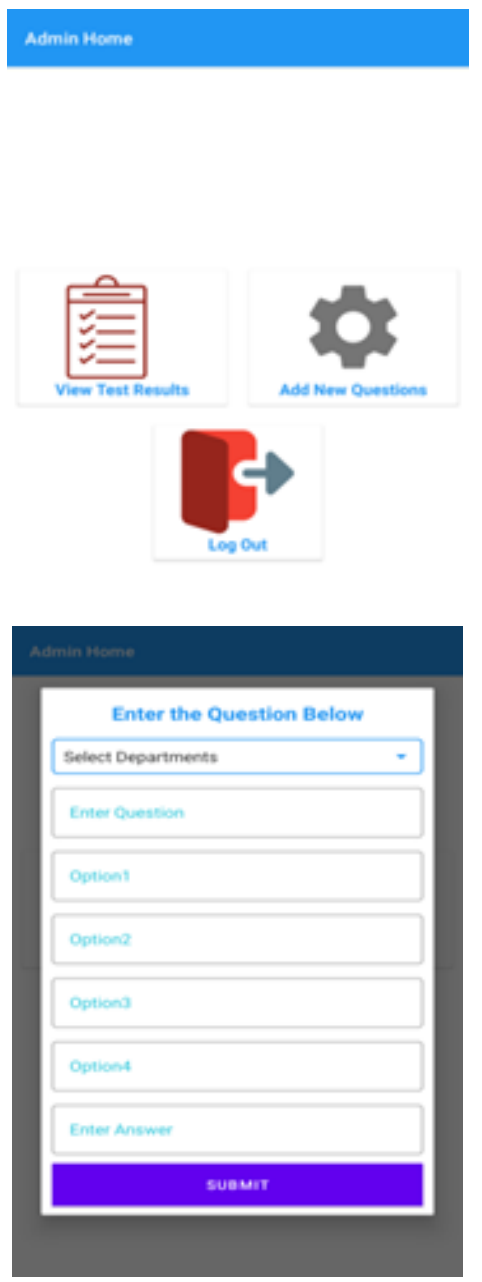

Admin Selecting Students based on results and adding new questions

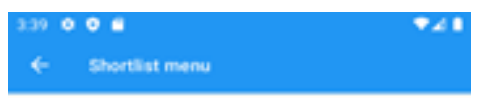

Test Results
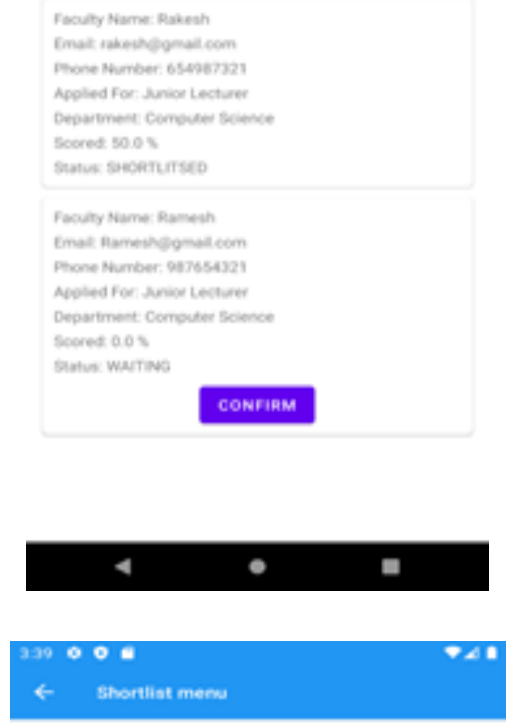

Test Results

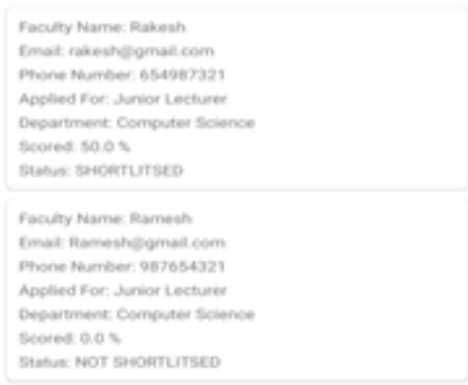

Succesunuy updated

4

-

=

\section{CONCLUSION}

Our Application Concludes by developing a best solution in the means of mobile application for helping college management system in choosing right faculty and sorting out candidates at the times of drives happening for faculty recruitment.

\section{FUTURE ENHANCEMENT}

Further we can add up features like Live video sessions for further interview rounds by maintain social distance. 


\section{VII.REFERENCES}

[1]. S. Strohmeier and F. Piazza, "Domain driven data mining in human resource management", A review of current research. Expert Syst. Appl, vol. 40, no. 7, pp. 2410-2420, 2013.

[2]. M. Kessler et al., "A hybrid approach to managing job offers and candidates", Inf. Process. Manage, vol. 48, no. 6, pp. 1124-1135, 2012.

[3]. C. Bizer et al., "The impact of semantic web technologies on job recruitment processes", Wirtschaftsinformatik. Physica-Verlag HD, pp. 1367-1381, 2005.

[4]. M. Mochol, H. Wache and L. Nixon, "Improving the Accuracy of Job Search with Semantic Techniques" in Business Information Systems, Springer Berlin Heidelberg, pp. 301313, 2007.

[5]. F. García-Sánchez et al., "An ontology-based intelligent system for recruitment", Expert Systems with Applications, vol. 31, no. 2, pp. 248-263, 2006.

[6]. N.J. Belkin and W.B. Croft, "Information filtering and information retrieval: two sides of the same coin?" Commun. ACM, vol. 35(12), 1992, pp. 29-38.

[7]. R. Kessler, et al., "Job Offer Management: How Improve the Ranking of Candidates," in Foundations of Intelligent Systems, J. Rauch, et al., Editors., Springer Berlin Heidelberg, 2009, pp. 431-441

[8]. E. Faliagka, Ramantas, K., Tsakalidis, A., Viennas, M., Kafeza, E., \&Tzimas G. (2011), "An Integrated E-Recruitment System for CV ranking based on AHP," in the Proceedings of the 7th Web Information Systems and Technologies (WEBIST 2011), 6-9 May, Netherlands, SciTePress, ISBN 978-989-842551-5, 2011, pp. 147-150.

[9]. F. Trichet, et al., "Human resource management and semantic Web technologies," in
Information and Communication Technologies: From Theory to Applications, 2004. pp. 641642.

[10]. M.Mochol, E. Paslaru, and B. Simperl, Practical guidelines for building semantic erecruitment applications. International Conference on Knowledge Management, Special Track: Advanced Semantic Technologies (AST'06), 2006, pp. 1-8

\section{Cite this article as :}

C. Siva Kumar, L. Sharath Kumar, C. Muthyalappa, D. Y. Shruthi, S. Shareena, D. Sireesha, " An Integrated College Faculty Recruitment System", International Journal of Scientific Research in Science and Technology(IJSRST), Print ISSN : 2395-6011, Online ISSN : 2395-602X, Volume 8, Issue 3, pp.632-637, May-June-2021. Available at doi $\quad$ : https://doi.org/10.32628/IJSRST2183140 Journal URL : https://ijsrst.com/IJSRST2183140 